Journal of Applied Fluid Mechanics, Vol. 2, No. 1, pp. 45-53, 2009.

Available online at www.jafmonline.net, ISSN 1735-3572, EISSN 1735-3645.

DOI: $10.36884 / \mathrm{jafm} .2 .01 .11856$

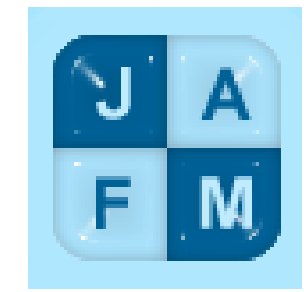

\title{
Simulation of Water Movement through Unsaturated Infiltration- Redistribution System
}

\author{
T. Bunsri ${ }^{1}$, M. Sivakumar ${ }^{2}$, and D. Hagare ${ }^{3}$ \\ ${ }^{1}$ National Center of Excellence for Environmental and Hazardous Waste Management (NCE-EHWM), Department of \\ Environmental Engineering, Faculty of Engineering, King Mongkut's University of Technology Thonburi, Bangkok 10140, \\ Thailand \\ ${ }^{2}$ Sustainable Water and Energy Research Group (SWERG), School of Civil, Mining and Environmental Engineering, \\ Faculty of Engineering, University of Wollongong, NSW 2522, Australia \\ ${ }^{3}$ Sterling College, Level 3, 770 George Street, Sydney, NSW 2000, Australia \\ Email: thidarat.bun@kmutt.ac.th
}

(Received January 16, 2008; accepted May 11, 2008)

\begin{abstract}
This paper deals with the movement of water in a natural unsaturated zone, focusing on infiltration-redistribution system. Infiltration refers to the downward movement of water due to the gravitational force and redistribution defines the upward movement of water due to the capillary rise. Under natural conditions, the movement of water through an infiltrationredistribution depended upon the relations among water content, hydraulic conductivity and tension of soil pore. Various combinations of water balance concepts, Richards' equation, soil-physics theory and capillary height concepts were applied to mathematically model the movement of water through infiltration-redistribution system. The accuracy and computational efficiency of the developed model were evaluated for the case study. Besides the laboratory scale sand/soil columns with the inner diameter of $10.4 \mathrm{~cm}$ were investigated in order to provide the supporting data for model calibration. Sand/soil layers were packed with a bulk density of 1.80 and $1.25 \mathrm{~g} / \mathrm{cm}^{3}$, respectively. The infiltration was sprayed uniformly at the soil surface with the constant rate of 66.1 and $7.18 \mathrm{~cm}^{3} / \mathrm{h}$ for sand and soil columns, respectively. The redistribution process was developed by which water arriving at the column base enter to the sand/soil column due to capillary rise. The laboratory observations were simulated using the developed model. The results indicate that the developed model could well estimate the movement of water in the infiltration-redistribution system that observed in the case study and the experiments.
\end{abstract}

Keywords: infiltration-redistribution system, numerical model, sand and soil column test, variably saturated soil conditions, water movement model.

\section{NOMENCLATURE}

$g \quad$ gravitational acceleration; $\mathrm{cm} \mathrm{h}^{-2}$

$h_{C} \quad$ capillary height, $\left(=2 T_{S} /\left[\rho_{w} g R\right]\right) ; \mathrm{cm}$

$k_{r w} \quad$ relative conductivity coefficient, $0 \leq k_{r w} \leq 1$; unitless

$K_{S} \quad$ saturated hydraulic conductivity; $\mathrm{cm} \mathrm{h}^{-1}$

$K_{S} k_{r w}$ relative hydraulic conductivity parameters; $\mathrm{cm} \mathrm{h}^{-1}$

$m \quad$ hydraulic properties coefficient; unitless

$M \quad$ specific moisture capacity, $(\partial \theta / \partial \psi) ; \mathrm{cm}^{-1}$

$n \quad$ hydraulic properties coefficient; unitless

$N_{i} \quad$ stiffness functions in local coordinate of each element $e$ in a domain $[0, \mathrm{~L}]$; unitless

$N_{j} \quad$ linear basis functions; unitless

$p \quad$ hydraulic properties coefficient; $\mathrm{cm}^{-1}$

$q \quad$ Darcy velocity; $\mathrm{cm} \mathrm{s}^{-1}$

$R \quad$ curvature radius of the meniscus; $\mathrm{cm}$

$t$ time; hour
$T_{S} \quad$ surface tension; $\mathrm{g} \mathrm{cm} \mathrm{s}^{-2}$

$z \quad$ vertical direction (positive upward); $\mathrm{cm}$

$\rho_{w} \quad$ water density; $\mathrm{g} \mathrm{cm}^{-3}$

$\theta \quad$ volumetric water content; $\mathrm{cm}^{3} \mathrm{~cm}^{-3}$

$\theta_{s} \quad$ saturated moisture contents; $\mathrm{cm}^{3} \mathrm{~cm}^{-3}$

$\theta_{r} \quad$ residual moisture contents; $\mathrm{cm}^{3} \mathrm{~cm}^{-3}$

$\psi \quad$ pressure head; $\mathrm{cm}$

$\psi_{C} \quad$ hydraulic pressure head at the capillary height; $\mathrm{g} \mathrm{cm} \mathrm{s}^{-2}$

$\psi_{j}(t) \quad$ nodal pressure head; $\mathrm{cm}$

$\psi_{\text {top }} \quad$ pressure head at the surface of column; cm

subscribe

$i, j, k$ number of nodes on the domain; unitless

superscript

$t, t+\Delta t$ previous and current time steps; unitless 


\section{INTRODUCTION}

The movement of water in a natural soil starts from a soil surface and end at a groundwater reservoir. The flow process of water from soil surface into the soil is called infiltration. The redistribution process refers to the upward movement of saturated zone into the unsaturated soil due to surface tension. The estimation of movement of water through the infiltration-redistribution system is an important issue for water resource management (Dingman 1994; Wurbs and James 2001). Many studies attempt to describe the infiltration flow in the unsaturated zone (Bouwer 1978, Bear 1979, Freeze and Cherry 1979, Fetter 1992, Huyakorn et al. 1984, Paniconi et al. 1991, Warrick et al. 1991 and Ségol 1993). However, studies of flow in an infiltrationredistribution system are rare. Therefore, the water movement model was developed as an alternative tool for predicting of water flow in the infiltration-redistribution system.

Water movement in partially saturated soil is technically described using Richards' equations (Richards 1931). Many numerical techniques were applied to solve Richards' equations (Huyakorn and Pinder 1983; Sudicky and Huyakorn 1991) including the integrated finite difference (Narasimhan and Witherspoon 1976), the control volume finite element (Therrien and Sudicky 1996) and Galerkin's finite element (Huyakorn et al. 1986; Simůnek and Suarez 1994). Among these techniques, Galerkin's finite element method was the most simply and effective way to solve Richards' equation. Picard's iteration technique could estimate the approximate solutions of Richards' equation effectively (Paniconi et al. 1991; van Genuchten and Sudicky 1999). The hydraulic properties parameters contained in Richards' equation were traditionally determined using van Genuchten model (van Genuchten et al. 1980; Kramer and Cullen 1995). The model development processes were described in this paper. The developed model was then calibrated using the data governed from the case study and the experiments. The calibration process was carried out to evaluate the model stability and reliability.

\section{NuMERICAL MODEL DEVElOPMENT}

\subsection{Flow in unsaturated porous media}

The one-dimensional vertical flow in unsaturated soil conditions could be described using Richards' equation as (Ségol 1993):

$$
M \frac{\partial \psi}{\partial t}=\frac{\partial}{\partial z}\left(K_{s} k_{r w}\left[\frac{\partial \psi}{\partial z}+1\right]\right)
$$

Galerkin's finite element method (weight residual method) was supported to the time and space discretisation of the pressure head functions. The approximate solution of pressure head was described as follows (Huyakorn and Pinder 1983; Huyakorn et al. 1984; Ségol 1993).

$$
\psi(z, t)=\sum_{j=1}^{k} \psi_{j}(t) N_{j}(z)
$$

The numerical solutions Eq. (1) were simplified as an ordinary differential equation as follows (Paniconi et al. 1991).

$$
\left[A_{i j}\right] \psi_{j}+\left[B_{i j}\right] \frac{\partial \psi_{j}}{\partial t}=\left\{E_{i}\right\}
$$

where

$$
\begin{aligned}
& {\left[A_{i j}\right]=\sum_{e} \int_{z=0}^{z=L} K_{S} k_{r w}\left(\frac{\partial N_{i}}{\partial z} \frac{\partial N_{j}}{\partial z}\right) d z ;\left[B_{i j}\right]=\sum_{e} \int_{z=0}^{z=L} N_{i} N_{j} M d z} \\
& \left\{E_{i}\right\}=\left.N_{i} K_{S} k_{r w}\left(\frac{\partial \psi}{\partial z}+1\right)\right|_{z=0} ^{z=L}-\sum_{e} \int_{z=0}^{z=L} K_{S} k_{r w} \frac{\partial N_{i}}{\partial z} d z
\end{aligned}
$$

These algebraic matrices presented in Eq. (3) were arranged with the linear Langrange basis functions. The solution of Richards' equation was obtained using the single Picard iteration technique. The schematic of iteration process is given as (Ségol 1993):

$$
\left(\frac{1}{2}\left[A_{i j}\right]^{t}+\frac{1}{\Delta t}\left[B_{i j}\right]^{t}\right)\left(\{\psi\}^{t+\Delta t}-\{\psi\}^{t}\right)=\left\{E_{i}\right\}-\left[A_{i j}\right]^{t}\{\psi\}^{t}
$$

\subsection{Soil hydraulic properties function}

Richards' equation contained the ideal parameters $M$ and $k_{r w}$ that could be estimated using van Genuchten (1980)'s hydraulic properties equations (Paniconi et al. 1991 and Fetter 1992). The equations are given as follows.

$$
\begin{aligned}
& \theta=\theta_{r}+\frac{\theta_{s}-\theta_{r}}{\left.1+(p|\psi|)^{n}\right]^{m}} \text { and } \\
& k_{r w}=\frac{\left[1-\left\{(p|\psi|)^{n-1}\left(1+[p|\psi|]^{n}\right)^{-m}\right\}\right]^{2}}{\left\{1+(p|\psi|)^{n}\right\}^{m / 2}}
\end{aligned}
$$

\subsection{Static capillarity equilibrium}

The equilibrium of capillary force; $\psi_{C}$ in soil porous media can be described using capillary height equation as follows (Fredlune \& Rahardjo 1940).

$\psi_{C}=-\rho_{w} g h_{C}$

The most difficult application of theory was the representation of the typically wide variability in the conditions that determined the infiltration process. Due to the limited understanding of this variability and the paucity of the field data, the developed model was simplified. Soil is assumed to be homogeneous along an indefinite depth and the water table level is stagnant. Surface of capillary fringe or impermeable layer is in horizontal that there is no evapotranspiration and no ponding. 


\subsection{Water balance error}

Richards' equation is the hyperbolic-parabolic partial differential equation and strongly non linearity. As Galerkin's finite element technique was applied to treat the non-linearity of Richards equation, it could present the mass lumping in finite element approximation. The oscillations of simulation results often occurred near the infiltration fronts. In order to reduce these oscillations, the mass balanced error is introduced as follows.

$M B(t+1)=\frac{\sum_{i=1}^{E-1}\left(\theta_{i}^{n+1}-\theta_{i}^{0}\right) \Delta z+\left(\theta_{0}^{n+1}-\theta_{0}^{0}\right) \frac{\Delta z}{2}+\left(\theta_{E}^{n+1}-\theta_{E}^{0}\right) \frac{\Delta z}{2}}{\sum_{k=1}^{n+1}\left(q_{0}^{k}-q_{L}^{k}\right) \Delta t}$

Where $M B(t+1)$ is the mass balance error at time step $t+1 . E$ is the number of element and $L$ is the number of nodes in the finite-element mesh $(L=E+1) . \quad q_{z o}$ and $q_{z L}$ are the boundary fluxes associated with $z_{0}$ and $z_{L}$, respectively. Superscripts " $n$ " and " $n+1$ " refer to the previous and current iteration step, respectively. Subscript 0 refers to node at the datum and superscript 0 refers to the initial iteration steps.

\section{MATERIALS AND METHODS}

The two soil samples utilized were medium grained sand and topsoil. Sand presented the uniform porous media whereas soil presented the non-uniform porous media. A sample of medium grained sand was prepared from a stock of river sand. The river sand sample was sieved with the particle size in range of $250-500 \mu \mathrm{m}$ (micron). The topsoil sample was collected near the Building 4-Engineering at the University of Wollongong, NSW, Australia. It was kept airdried and then sieved to remove rocks and organic impurities. The particle size of soil was less than $2.00 \mathrm{~mm}$. Random samples were selected according to the Australian Standards (AS Standards). The characteristics of sand and soil samples were provided in Table 1.

Laboratory scale soil column set up is presented in Fig. 1. The column was fabricated from a plexi-glass tube of 6.9 $\mathrm{cm}$ inside diameter. The length of the column was $30 \mathrm{~cm}$ (effective height $20 \mathrm{~cm}$ ). Jet fill tensiometer model $2100 \mathrm{~F}$ moisture probes were used to measure negative pore pressure (suction head). The datum was defined at the base of the column (positive upward). Five tensiometers were inserted at depth $2.5,6.5,10.0,14.0$ and $17.5 \mathrm{~cm}$ above the datum. Rubber plugs were inserted into the observation ports to prevent leakage. The tensiometers were connected to a data logger model DT 500 DataTaker. A 10 volts DC transformer supplied power to the data logger. Two tests were conducted: hydraulic properties (HP) and infiltrationredistribution column (CT) tests. The HP test was undertaken using the dynamic methods (Klute 1986). The column was initially packed with sand and soil samples. The packing depth was $5 \mathrm{~cm}$. The bulk densities of sand and soil columns were controlled at 1.80 and $1.25 \mathrm{~g} / \mathrm{cm}^{3}$, respectively. Time series data of pressure head was measured using a single tensiometer that was installed at the depth of $2.5 \mathrm{~cm}$ above the column base. Tap water was poured through the sand and soil column at the rates of 66.1 and $7.18 \mathrm{~cm}^{3} / \mathrm{h}$, respectively. The CT test was carried out by method modified from Yang et al. (2004). The column was initially packed with dry sand and soil samples. Sand and soil columns were packed with bulk densities of 1.80 and $1.25 \mathrm{~g} / \mathrm{cm}^{3}$, respectively. The columns were placed into the water storage tank. The water level was located at the column base. The columns were brought to an equilibrium condition while tap water was applied to the surface of the sand and soil columns at the rates of 66.1 and $7.18 \mathrm{~cm}^{3} / \mathrm{h}$, respectively. The water contents for both of HP and CT tests were analysed using AS 1289.2.1.11992. The details of these tests are provided in Table 2.

Table 1 Characteristics of sand and soil samples

\begin{tabular}{|l|c|c|}
\hline \multirow{2}{*}{ Parameters } & \multicolumn{2}{c|}{ Values } \\
\cline { 2 - 3 } & Sand & Soil \\
\hline Particle size analysis & & \\
Sand (\%) & 100 & 37.51 \\
Silt (\%) & 0 & 43.79 \\
Clay (\%) & 0 & 18.70 \\
Textural Classification & Sand & Loam \\
K $_{\mathrm{S}}(\mathrm{cm} / \mathrm{h})$ & 6.47 & 0.662 \\
Specific gravity & 2.65 & 2.55 \\
Bulk density (g/cm $\left.{ }^{3}\right)$ & 1.79 & 1.28 \\
Void ratio & 0.49 & 0.74 \\
Moisture content (\%) & 0.121 & 5.00 \\
\hline
\end{tabular}

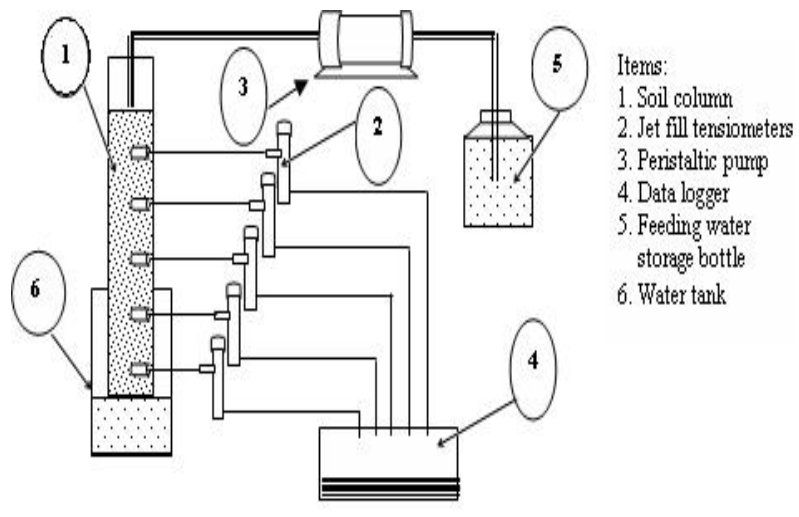

Fig. 1. Column setup.

Table 2 Details of column tests

\begin{tabular}{|c|c|c|c|c|c|}
\hline Tests & $\begin{array}{c}\text { Packing } \\
\text { depth } \\
\text { (cm) }\end{array}$ & $\begin{array}{c}\text { Packing } \\
\text { density } \\
\left(\mathrm{g} / \mathrm{cm}^{3}\right)\end{array}$ & $\begin{array}{c}\text { Feeding } \\
\text { rate } \\
\left(\mathrm{cm}^{3} / \mathbf{h}\right)\end{array}$ & $\begin{array}{c}\text { Tensiometer } \\
\text { locations } \\
\text { (cm-above } \\
\text { the column } \\
\text { base) }\end{array}$ & $\begin{array}{c}\text { Moisture } \\
\text { content } \\
\text { test }\end{array}$ \\
\hline $\begin{array}{l}\text { HP } \\
\text { Sand } \\
\text { soil }\end{array}$ & $\begin{array}{l}5 \\
5\end{array}$ & $\begin{array}{l}1.80 \\
1.25\end{array}$ & $\begin{array}{l}66.1 \\
7.18\end{array}$ & $\begin{array}{l}2.5 \\
2.5\end{array}$ & $\begin{array}{c}\text { Every } 1 \\
\text { cm } \\
\text { Every } 1 \\
\mathrm{~cm}\end{array}$ \\
\hline $\begin{array}{l}\text { CT } \\
\text { Sand } \\
\text { soil }\end{array}$ & 20 & $\begin{array}{l}1.80 \\
1.25\end{array}$ & $\begin{array}{l}66.1 \\
7.18\end{array}$ & $\begin{array}{l}2.5,6.5, \\
10.0,14.0, \\
17.5 \\
2.5,6.5, \\
10.0,14.0, \\
17.5 \\
\end{array}$ & $\begin{array}{c}\text { Every } 4 \\
\mathrm{~cm} \\
\text { Every } 4 \\
\mathrm{~cm}\end{array}$ \\
\hline
\end{tabular}




\section{RESUlTS AND DisCUSSIONS}

\subsection{Model validation with reference case study}

The model was calibrated using the case study proposed by Paniconi et al. (1991). This study was demonstrated a test for the water movement through the infiltration and redistribution column. An initial condition was controlled by a static equilibrium of capillary force. The simulation parameters are provided in Table 3. The Nuemann and the dirichlet conditions were applied to the upper and lower boundary, respectively. The pressure head and moisture content profiles are presented in Figs. 2 and 3, respectively.

The pressure head and moisture content profiles given in this reference case study presented the ideal vadose zone at which water table would stand at a given level. In general, the level of water table often changed seasons by seasons. The lowest portion of the column was a region that is saturated as a result of capillary rise. Besides, the water input events such as rainfall and storm could affect the infiltration rate. However, the rate of infiltration applied in the reference case study was constant. According to this ideal condition, it can be assumed that this column was operated with "no ponding" condition (Dingman 1994). The infiltration rate was less than or equal to infiltration capacity.

At initial the column achieved the equilibrium of redistribution, the pressure head distribution was reduced linearly along the elevation regarding the capillary rise (Fredlune and Rahardjo 1940). On the other hand, the moisture content profiles did not presented the same trend line as the pressure head profile. The reason for this claim was the relation between volumetric moisture content and pressure head presented in van Genuchten model was nonliner. So, the volumetric moisture content must be the average of several measurements. During the constant infiltration flux at surface, the pressure head at the column surface reduced constantly over time. The volumetric moisture content increased slightly over time, it was not constant. So too, this revealed that the capillary rise equation could be support to the pressure head profile simulation.

The simulations obtained from the developed model were not distinguishable from the data governed from reference. This implies that the developed model was robust and reliable and it could effectively support the estimation of water movement in the infiltration-redistribution systems. The static capillarity equilibrium presented in Eq. (6) was a valid boundary that could be support the system very well.

According to the pressure head simulation, the pressure distribution profile at initial revealed the steady-state of capillary rise. The water arrived at the surface due to capillary force; this can be called "redistribution". When the constant water input rate applied on the soil surface, water could enter to the soil pore faster than the rate of draining. Some amounts of water were stored in soil pore, decreasing the suction pressure at the column surface. The decrease of suction pressure caused an increase in hydraulic conductivity.
Table 3 Input parameters for Paniconi et al.'s test

\begin{tabular}{l|l}
\hline \multicolumn{1}{c|}{ Parameters } & \multicolumn{1}{c}{ Values } \\
\hline Domain & $10-\mathrm{m}$ soil column \\
Hydraulic properties & \\
parameters: & 5 \\
$K_{S}(\mathrm{~m} / \mathrm{h})$ & 0.45 \\
$\theta_{s}$ & 0.08 \\
$\theta_{r}$ & 3 \\
$n$ & 0.667 \\
$m$ & 0.333 \\
$p(1 / \mathrm{m})$ & \\
Boundary conditions: & The specified Darcy's \\
Upper (column surface) & flux; $q=t / 64 \mathrm{~m} / \mathrm{h}$. \\
& Constant pressure head; \\
Lower (column base) & $\psi=0 \mathrm{~m}$. \\
Initial pressure head & Static equilibrium with \\
& capillary pressure head; \\
& $\left(\psi_{C}=-0.19105548 \mathrm{~m}\right)$ \\
Nodal spacing; $\Delta \mathrm{z}$ & $0.01 \mathrm{~m}$ uniform grid with \\
& 100 elements \\
Time interval; $\Delta \mathrm{t}$ & 0.01 hour \\
\hline
\end{tabular}

As long as the hydraulic conductivity equaled the water feeding rate, the column surface would be fully saturated. Therefore, the inflow rate equals the rate of outflow from the soil column, so there was no further change in pressure head profiles. This case study could successively present the infiltration-redistribution system under the continuous water input rate, which described the early stages of infiltration. If water feeding was excess, it would accumulate on the surface as ponding.

With regard to the moisture content profiles, they also showed the perfectly sharp wetting front at the column surface. When the surface layer became nearly saturated, the wetting front further moves downwards at depth of 3 $\mathrm{m}$ at 32 hours. The shapes of moisture content and pressure head profiles were the same.

\subsection{Model validation with experimental data}

The hydraulic properties of these utilised media were fitted using van Genuchten's equations. The obtained water retention curves are presented in Fig. 4. The coefficients for the hydraulic properties of sand and soil are summarised in Table 4. The fully saturated permeabilities $\left(\mathrm{K}_{\mathrm{s}}\right)$ of sand and soil samples were 6.47 and $0.662 \mathrm{~cm} / \mathrm{h}$, respectively.

The applied pressure head at the upper boundary condition of the simulation was estimated using the Green-Ampt (1911) equations (cited in Dingman 1994). The pressure heads at the wetting front for sand and soil samples were $6.95 \pm 8.00$ and $-30.7 \pm 27.4 \mathrm{cmH}_{2} \mathrm{O}$, respectively. The observed pressure head of sand column was $-5.0 \mathrm{cmH}_{2} \mathrm{O}$ and the pressure head of soil column ranged from -17.5 to $-10.0 \mathrm{cmH}_{2} \mathrm{O}$. The input parameters for water movement through an infiltration-redistribution system in sand and soil columns are given in Table 5.

Firstly, the simulation was undertaken on sand infiltrationredistribution column test. The pressure head profiles are 
T. Bunsri et. al / JAFM, Vol. 2, No. 1, pp. 45-53, 2009.

presented in Fig. 5. Water percolated through the system very slowly.
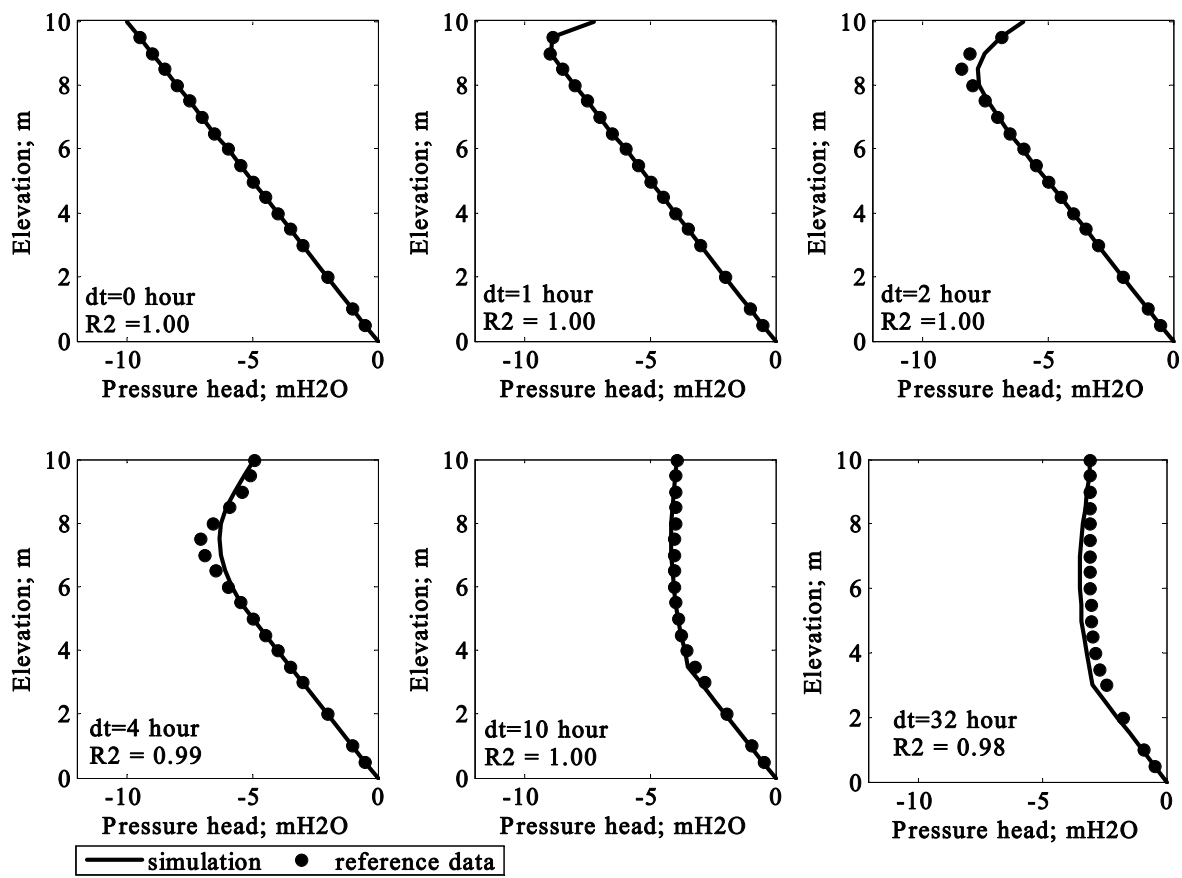

Pressure head; $\mathrm{mH} 2 \mathrm{O}$

Fig. 2. Simulation of pressure head profiles for Paniconi et al.'s test.
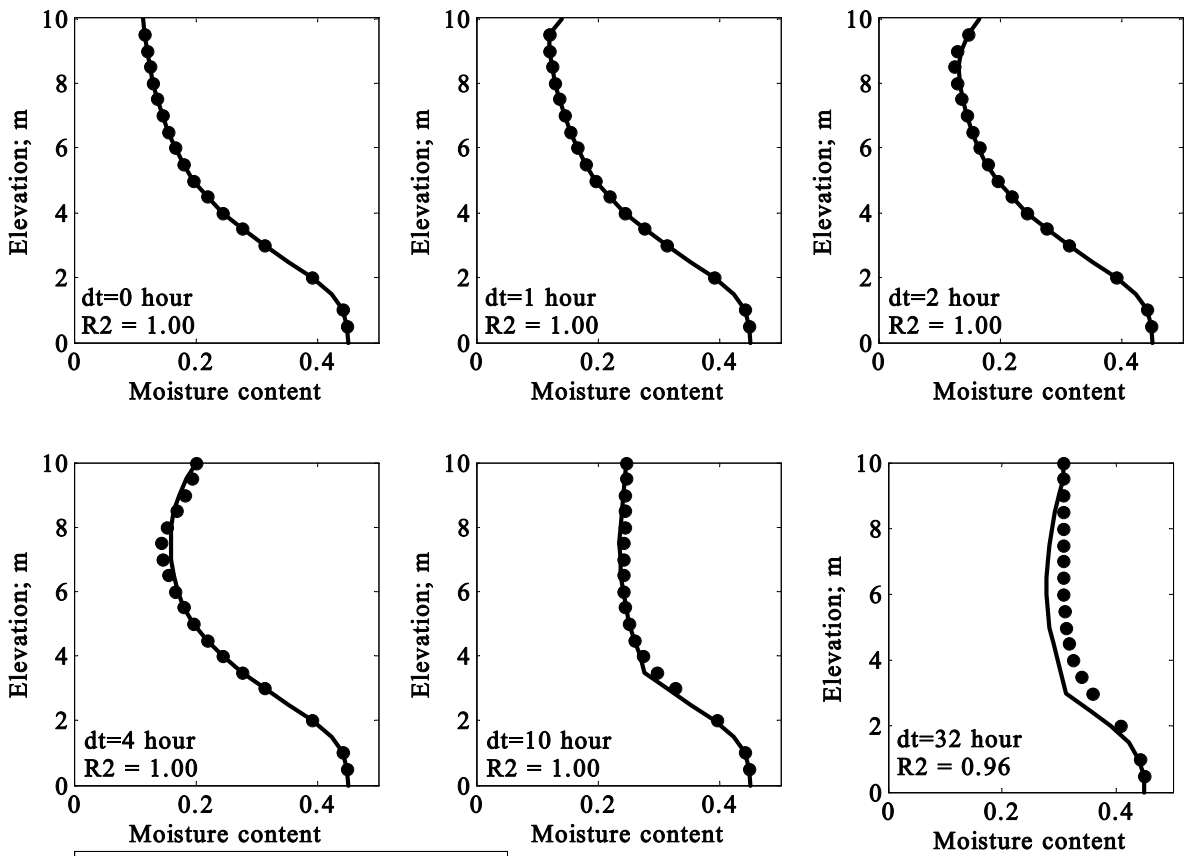

Fig. 3. Simulation of moisture content profiles for Paniconi et al.'s test. 

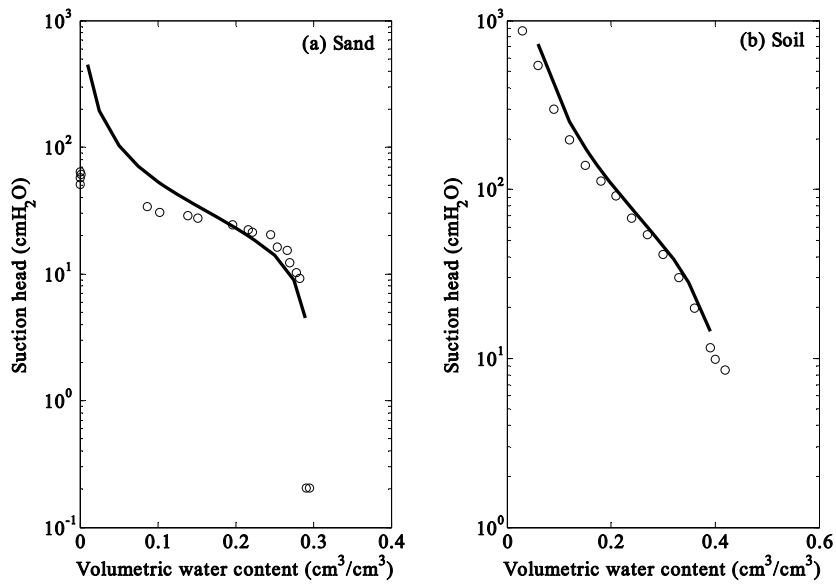

Fig. 4. Hydraulic retention curves of sand (a) and soil samples (b).

Table 4 Coefficients of sand and soil hydraulic properties

\begin{tabular}{|l|c|c|}
\hline \multicolumn{1}{|c|}{ Parameters } & Sand & Soil \\
\hline$\theta_{\mathrm{s}}$ & 0.30 & 0.42 \\
$\theta_{\mathrm{r}}$ & 0.07 & 0.04 \\
$m$ & 0.5378 & 0.4026 \\
$n$ & 2.1636 & 1.6740 \\
$p ; \mathrm{cm}^{-1}$ & 0.0446 & 0.0249 \\
\hline
\end{tabular}

Table 5 Input parameters for sand and soil column tests

\begin{tabular}{|c|c|}
\hline Parameters & Values \\
\hline Domains & $20 \mathrm{~cm}$ \\
\hline Boundary conditions & $\begin{array}{l}\text { Initial conditions refer to Eq (6) and } \\
\text { the reading pressure head. }\end{array}$ \\
\hline Hydraulic properties & Refer to Table 4 \\
\hline Time domain & $\begin{array}{l}3 \text { hours (sand column) and } 8 \text { hours } \\
\text { (soil column) }\end{array}$ \\
\hline $\begin{array}{l}\text { No. of time step/ hour; } \\
n t\end{array}$ & $\begin{array}{l}\text { Varies from } 300-1200 \text { (sand) and } 800- \\
2400 \text { (soil) }\end{array}$ \\
\hline Nodal spacing; $\Delta z$ & $0.25 \mathrm{~cm}$ \\
\hline
\end{tabular}

Darcy velocities were $-0.0015,-0.0023,-0.0029$ and $-0.0071 \mathrm{~cm} / \mathrm{h}$ at $0.5,1.0,2.0$ and 3.0 hours, respectively. The saturation zone moves downward due to the infiltration. The driest zone was appeared at the elevation of 14-17.5 cm during 1-3 hours testing. The driest zone disappeared, after hours continuous feeding. The pressure head of whole column was constant at -5.45 $\mathrm{cmH}_{2} \mathrm{O}$. The equilibrium of inflow-outflow was achieved if $|\psi| \approx K_{S} \quad$ (Dingman 1994). This could be assumed that the sand columns were close to the equilibrium within 4 hours. The developed model generates a good fit to the observed data. The reliability of estimating result was very high as the range of $\mathrm{R}^{2}$ was $0.84-0.98$.

The volumetric moisture content profiles are presented in Fig. 6. The simulation generated similar moisture content profiles to the laboratory data. Almost three quarters of columns were full of water that rose due to the capillary force. The driest point of sand column appeared at the elevation of 17.5 and $13.5 \mathrm{~cm}$ at 1.0 and
2.0 hours, respectively. The shape of the moisture content profiles was the same as for the pressure head. The simulations generate the acceptable trend for moisture content profiles. However the $\mathrm{R}^{2}$ values were very low when the column nearly reached the equilibrium at 2 and 3 hours. This might be the limitation of the hydraulic properties model, as it cannot well capture the changing of volumetric moisture content at nearly saturated condition.

Secondly, the model was applied to estimate the water movement in soil infiltration-redistribution system. The pressure head profiles are presented in Fig. 7. Water migrated slowly with Darcy's velocities of $-3.84 \times 10^{-5}$, $4.78 \times 10^{-4},-6.84 \times 10^{-4}$ and $-9.67 \times 10^{-4} \mathrm{~cm} / \mathrm{h}$ at $2.0,4.0,6.0$ and 8.0 hours, respectively. The velocities increased nonlinearly over time. As expected, these velocities were lower than in sand column. Redistribution could pull the water through the soil quicker than the sand, due to the size of pores. The driest point on the column was observed at the elevation of $14-17.5 \mathrm{~cm}$ until 8 hours. The pressure head profiles slightly change. This might relate to the low permeability and high porosity of soil that could resist the infiltration. The pressure head on column surface; $\psi_{\text {top }}$ was in the range of -10.25 to $15.75 \mathrm{cmH}_{2} \mathrm{O}$. When $\psi_{\text {top }}<K_{S}$, it reveals that the soil columns did not achieve the equilibrium condition. The oscillation in simulations was omitted as the high $\mathrm{R}^{2}$ were obtained.

The moisture content profiles were provided in Fig. 8 . The moisture content changed in a narrow range from 0.38 to 0.42 . The lowest moisture content was constant at 0.38 and it was observed at the elevation of $18.0 \mathrm{~cm}$. The simulation indicates the fair agreement with the observation data. The trend of moisture content profiles was similar to the pressure head profiles.

The developed model could precisely estimate pressure head profiles in both media. 
T. Bunsri et. al / JAFM, Vol. 2, No. 1, pp. 45-53, 2009.
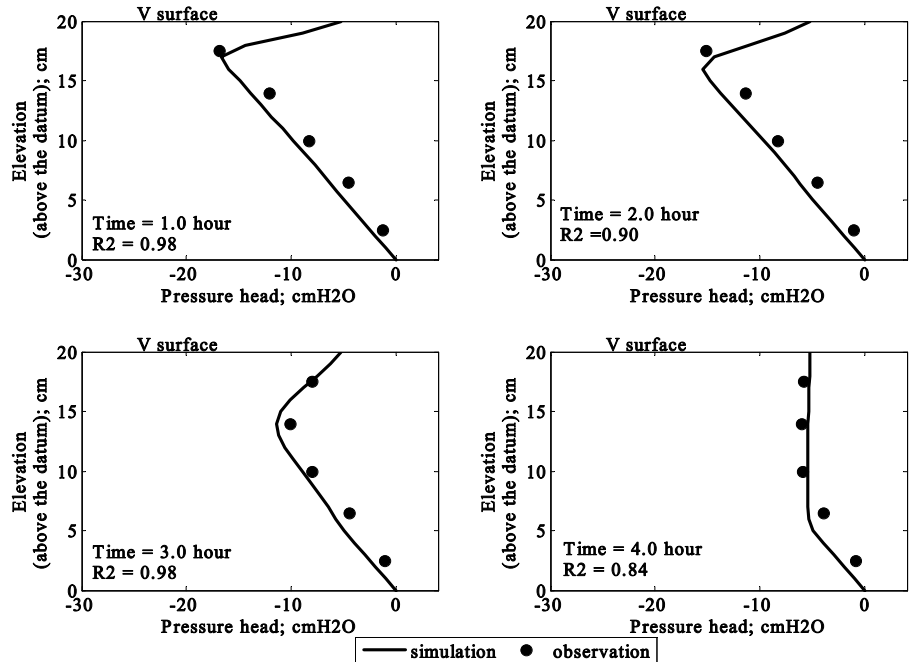

Fig. 5. Pressure head profiles of sand column test.
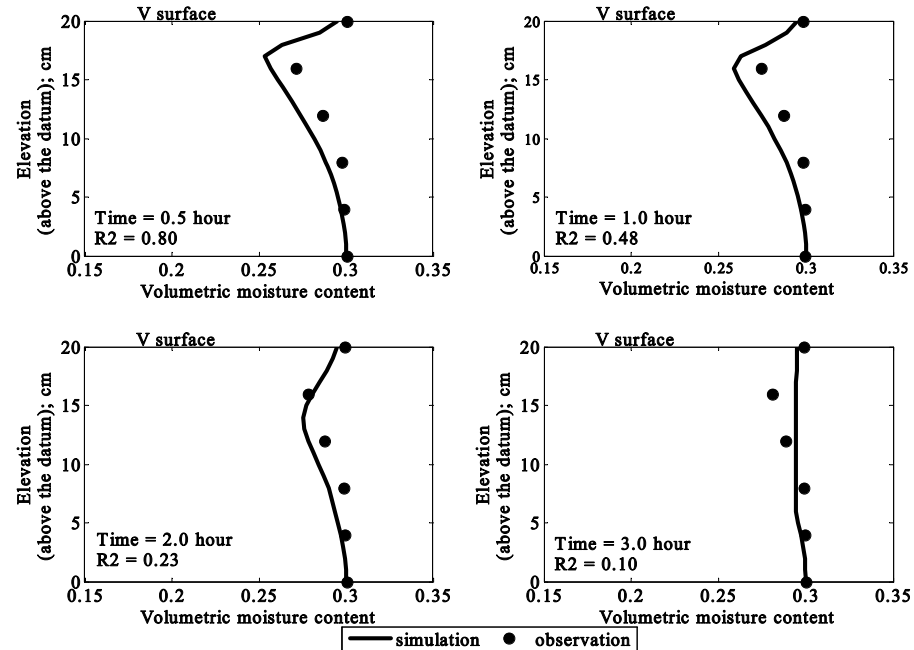

Fig. 6. Moisture content profiles of sand column test.
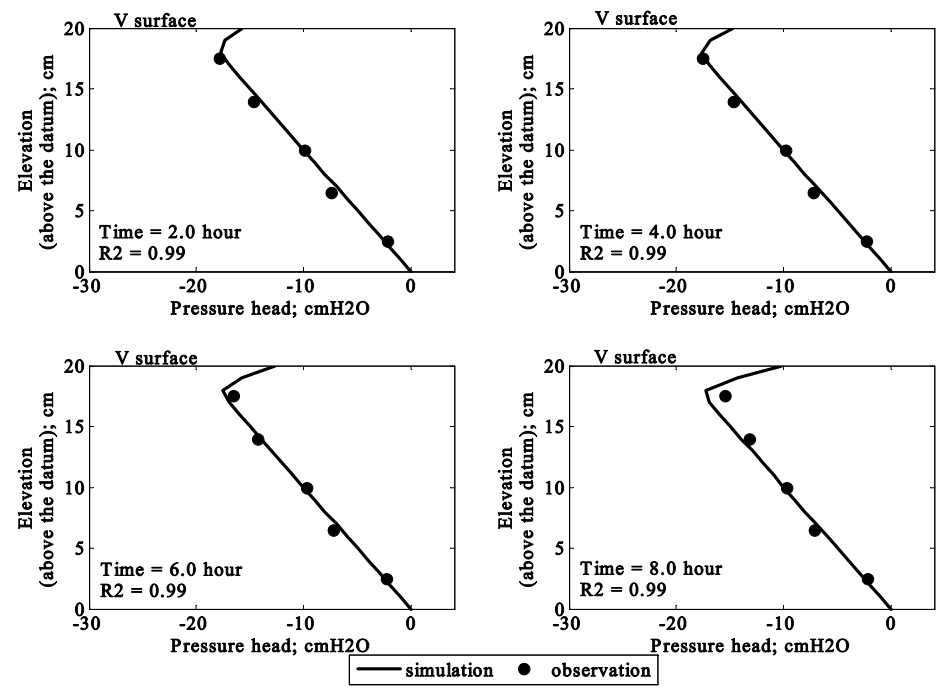

Fig. 7. Pressure head profiles of soil column test. 

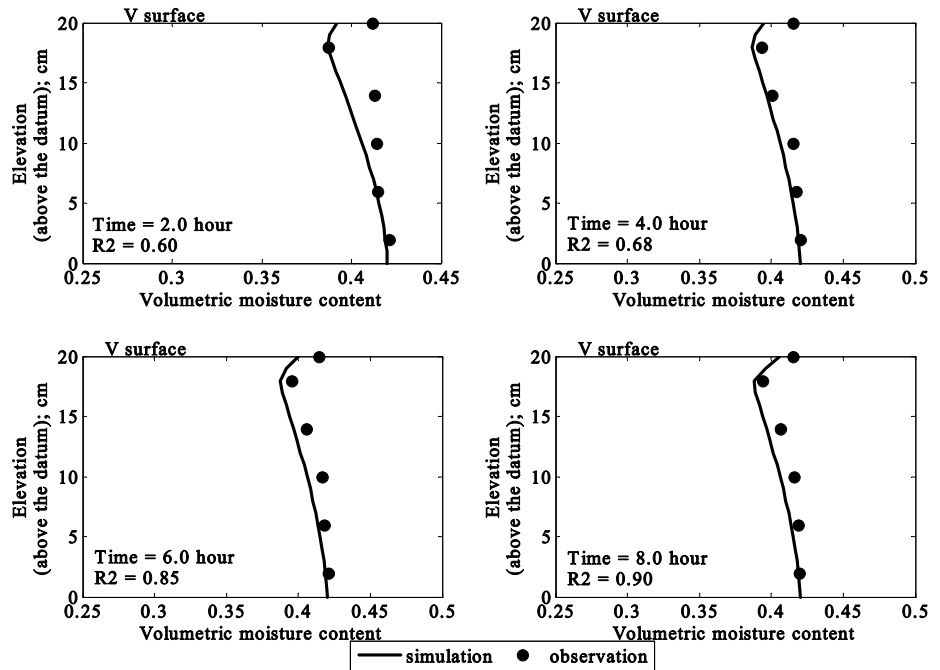

Fig. 8. Moisture content profiles of soil column test.

This might be the result of time varying boundary conditions applied as these conditions could be measure precisely using a series of tensiometers. The model developed in this research is effectively tool for estimating the water movement in the infiltrationredistribution system.

\section{CONCLUSION}

Infiltration-redistribution was found to be the simplest natural system, especially in the drainage areas. Water movement through the infiltration-redistribution was very complicate system; there were upward and downward directed pressure gradients due to gravity drainage and capillary rise. Richards' equation was applied to determine the infiltration-redistribution unsaturated flow. The static equilibrium capillary equation was applied as initial and boundaries conditions. The developed model generates the accurate pressure head and moisture content profiles that could describe the flow pattern undertaken from the reviewed case study and the experiments.

Since the ideal conditions were applied, the infiltrationredistribution system was simplified. The simulation could describe the theoretical and practical the variable and behaviour of soil-water in natural process. Just before input water began, the pressure head was distributed due to the equilibrium of capillary rise. At an initial, feeding water began moving at the surface of column at a constant rate and continued at this specified rate for a considered time. Feeding water moved through the soil pore faster than the rate of drainage. The water was stored in the soil pores, this caused and increase of volumetric water content and hydraulic conductivity. So far, volumetric water content and hydraulic conductivity were continued to increase, until the rate of inflow equals to the rate of outflow, there was no further change in both pressure head and moisture content profiles. After the column reached the equilibrium of inflow-outflow rate, the column surface would be saturated. If feeding water was continued to apply, the excess water could be accumulated on the surface of column as ponding. Both case study and experiments could successively validate the model, typically the early stage of infiltration in natural soil. Normally, the natural drainage field was designed to avoid ponding or runoff, so, this model might be applied to a simple natural drainage system.

\section{ACKNOWLEDGMENT}

Funding support for this research was provided through PhD. scholarship to T. Bunsri by National Research Centre for Environmental and Hazardous Waste Management (NRC-EHWM), and King Mongkut's University of Technology Thonburi, Bangkok, Thailand.

\section{REFERENCES}

Australian Standard (1992). Methods of testing soils for engineering proposes, Methods 2.1.1: soil moisture content tests-Determination of the moisture content of a soil- oven drying method. AS 1289.2.1.1-1992.

Bear, J. (1979). Hydraulics of groundwater. New York, McGraw Hill.

Bouwer, H. (1978). Groundwater hydrology. New York, McGraw Hill.

Dingman, S.L. (1994). Physical hydrology. New Jersey, Prentice Hall.

Fetter C.W. (1992). Contaminant hydrology. New York, Macmillan Publishing.

Fredlune D.G. and H. Rahardjo (1940). Soil mechanics for unsaturated soils. New York, John Wiley \& Sons. 
Freeze, R.A. and J.A. Cherry (1979). Groundwater. New Jersey, Prentice-Hill.

Huyakorn, P.S. and G.F. Pinder (1983). Computational methods in subsurface flow. New York, Academic Press.

Huyakorn, P.S., E.P. Springer, V. Guvannasen, and T.D. Wadsworth (1986). A three-dimensional finiteelement model for simulating water flow in variably saturated porous media. Water Resources Research $22,1790-1808$.

Huyakorn, P.S., S.D. Thomas, and B.M. Thompson (1984). Technique for making finite element competitive in modeling flow in variably saturated porous media. Water Resources Research 20(8), 1099-1115.

Klute, A. (1986). Water retention: laboratory methods. In A. Klute (Ed.), Method of soil analysis, Part 1 Physical and mineralogical methods, Agronomy, 635-662.

Kramer, J. H. and S.J. Cullen (1995). Review of vadose zone flow and transport models. In L.G., Wilson, Everett, L.G and Cullen, S.J. (Eds.), Handbook of vadose zone characterization \& monitoring, 267289.

Narasimhan, T.N. and P.A. Witherspoon (1976). An integrated finite difference method for analyzing fluid flow in porous media. Water Resources Research 12(1), 57-64.

Paniconi, C., A.A. Aldama, and E.F. Wood (1991). Numerical evaluation of iterative and noniterative methods for the solution of the nonlinear Richards equation. Water Resources Research 27(6), 11471163.

Richards, L.A. (1931). Capillary conduction of liquids through porous mediums. Physics 1, 318-333.
Ségol, G. (1993). Classical groundwater simulations: Proving and improving numerical models. New Jersey, PTR Prentice Hall.

Šimůnek, J. and D.L. Suarez (1994). Two-dimensional transport model for variably saturated porous media with major ion chemistry. Water Resources Research 30(4), 1115-1133.

Sudicky, E.A. and P.S. Huyakorn (1991). Contaminant migration in imperfectly know heterogeneous groundwater systems. Reviews of geophysics, supplement, U.S. National Report to the International Union of Geodesy and Geophysics 29 (1987-1990), 240-253.

Therrien, R. and E.A. Sudicky (1996). Threedimensional analysis of variably-saturated flow and solute transport in discretely-fractured porous media. Journal of Contaminant Hydrology 23, 1-44.

van Genuchten, M.Th. (1980). A closed-form equation for predicting the hydraulic conductivity of unsaturated soils. Soil Science Society of America Journal 44, 892-898.

van Genuchten, M.Th. and E.A. Sudicky (1999). Recent advances in vadose zone flow and transport modeling. In M.B. Parlang and J.W. Hopmans (Eds.) Vadose zone hydrology: cutting across disciplines, 155-193.

Warrick, A.W. (1991). Numerical approximations of Darcian flow through unsaturated soil. Water Resources Research 27(6), 1215-1222.

Wurbs, R.A. and W.P. James (2001). Water resources engineering. New Jersey, Prentice Hall.

Yang, H., H. Rahardjo, B. Wibawa, and E.C. Leong (2004). A soil column apparatus for laboratory infiltration study. Geotechnical Testing Journal 27(4), 347-355. 